\title{
Legal Uncertainty, Competition Law Enforcement Procedures and Optimal Penalties ${ }^{1}$ \\ Yannis Katsoulacos ${ }^{2} \&$ David Ulph $^{3}$
}

This version: March 2015

\begin{abstract}
In this paper we make three contributions to the literature on optimal Competition Law enforcement procedures. A first contribution, of more general interest, is to clarify the concept of "legal uncertainty", relying on ideas in the literature on Law and Economics, but formalising it by associating legal uncertainty with the information structure of what firms know about the process by which potentially harmful actions are treated by competition authorities. What firms know is clearly distinct, though influenced, from the decision errors made by authorities. We use this framework to show that information structures with legal uncertainty need not imply lower welfare than information structures with legal certainty - a result echoing a similar finding obtained in a completely different context and under different assumptions in earlier Law and Economics literature (Kaplow and Shavell, 1992). Our second contribution is to revisit and significantly generalise the analysis in our previous paper, Katsoulacos and Ulph (2009), involving a welfare comparison of Per Se and Effects-Based legal standards. In that analysis we considered just a single information structure under an Effects-Based standard and also penalties were exogenously fixed. Here we allow (a) for different information structures under an Effects-Based standard and (b) for endogenous penalties. We obtain two main results. Under all information structures (including complete legal uncertainty) an Effects-Based standard dominates a Per Se standard. Moreover, optimal penalties may be higher when there is legal uncertainty than when there is no legal uncertainty. These conclusions run counter to a number of prescriptions by legal scholars in the recent literature.
\end{abstract}

JEL: K4, L4, K21, K23

Keywords: competition law enforcement, penalties, legal uncertainty, competition policy.

\footnotetext{
${ }^{1}$ Previous versions of this paper have been presented at Seminars at the University of Sussex, September 2011; the Higher School of Economics, Moscow, April 2013; the MaCCI Workshop on Competition Policy, Speyer, 13 - 17 June 2011; at Workshops in the Office of Fair Trading and the French Competition Authority in January 2011; the CRETE Conference, Tinos, Greece, July 12, 2010, the Centre for Competition Policy Conference, Norwich, June 2012 and the EARIE Conference, Rome September 2012. We have particularly benefitted from the comments of Mathew Bennett, Amelia Fletcher, Kai-Uwe Kuhn, Massimo Motta, Volker Nocke, Martin Peitz, Anne Perrot, Michele Polo, Patrick Rey, Yossi Spiegel, Jean Tirole and Thibaud Verge. Also, we are grateful for the comments of three referees. Of course, all errors and ambiguities remain solely our responsibility. The research was undertaken as part of a research project on optimal enforcement procedures funded by the UK Economic and Social Research Council (ESRC) under grant RES-062-23-2211. It has been co-financed by the European Union (European Social Fund ESF) and Greek national funds through the Operational Program "Education and Lifelong Learning" of the National Strategic Reference Framework (NSRF) - Research Funding Program: CoLEG

${ }^{2}$ Professor, Dept. of Economics, Athens University of Economics and Business; E-mail: ysk@hol.gr

${ }^{3}$ Professor, School of Economics \& Finance, University of St. Andrews, and Director of Scottish Institute for Research

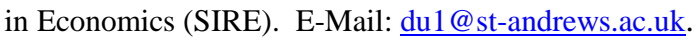




\section{Introduction}

It is widely argued that, when deciding what type of procedures to use to enforce regulatory intervention in markets, an important consideration is the degree of legal uncertainty ${ }^{4}$ - the extent to which agents know, at the time they decide to take an action, what decision a regulatory authority will make as to whether to allow or disallow (and possibly penalise) the agent's action should it ever be investigated by the authority. Certain enforcement procedures are advocated in policy circles as being superior, ceteris paribus, because the legal uncertainty ${ }^{5}$ they generate is relatively low.

While this issue is important for a very broad range of regulatory interventions ${ }^{6}$ here we frame our discussion and analysis in the specific context of competition policy / law and its enforcement. Here discussions on legal uncertainty usually involve comparisons of Effects-Based ${ }^{7}$ enforcement procedures and Per Se enforcement procedures ${ }^{8}$. Under Per Se an entire class of actions is allowed (resp. disallowed), depending on whether their average harm ${ }^{9}$ is negative (resp. positive), whereas under Effects-Based procedures, the Competition Authority (CA) will investigate actions, and allow (resp. disallow) them if some estimate of their individual harm is negative (resp. positive) ${ }^{10}$. It is argued that under a Per Se rule firms are certain how their action will be treated if it ever comes

\footnotetext{
${ }^{4}$ Legal scholars and social scientists have, of course, discussed the issue of legal uncertainty in a much wider context than that of economic regulation. Among early prominent authors, Max Weber, thought of legal certainty as necessary for capitalist progress - see discussion in D'Amato (1983) with extensive references to legal scholars including Posner ( $8^{\text {th }}$ edition, 2010). For a discussion of the importance of legal certainty by a EU competition law expert, see Forrester's (2000) account in the context of Competition Policy. In Section 3 we provide a review of the extensive Law and Economics (mainly US) literature that has examined over many years various implications of legal uncertainty for law enforcement.

${ }^{5}$ Or, lack of ability to predict the outcome of a legal dispute. D'Amato (1983) defines "legal uncertainty" as a "situation that obtains when the (legal) rule that is relevant to a given act or transaction is said by informed attorneys to have an expected official outcome at or near the 0.5 level of predictability". For a recent extensive treatment by a legal expert see Kevin E. Davis (2011).

${ }^{6}$ As has been recognised in the Law and Economics literature reviewed in Section 3. These include interventions associated with the application of Environmental Policy, determining eligibility for welfare benefits, Tax Compliance mechanisms, as well as, Competition Policy, Sectoral Regulation, etc.

${ }^{7}$ Sometimes alternatively called discriminating or Rule-of-Reason procedures. One can think of what in US is termed Rule-of-Reason as an extreme form of the Effects-Based approach under which competition authorities have the discretion to apply different economic methodologies and criteria on a case-by-case basis. For this last distinction see also Vickers (2007).

8 Often also referred to as object or form-based procedures.

${ }^{9}$ Usually it is "harm to others" that is the adopted criterion, or a consumer surplus substantive standard is used (see also below).

${ }_{10}$ This distinction is similar to the comparison between unconditional/rigid and conditional/flexible contracts. In the context of welfare policy the analogous distinction is of universal and targeted benefits.
} 
under scrutiny by a CA, whereas, under an Effects-Based approach, they do not know for sure what decision would be taken, and consequently this legal uncertainty induced by Effects-Based procedures should lead the CA to favour Per Se procedures. For example, in his classic article, after reviewing all the reasons why it is hard to have clarity as to the circumstances under which an action may in principle be harmful or benign, and the difficulties of obtaining data and carrying out the calculations required to implement whatever tests might be available, Easterbrook (1992) writes "Do we then abandon antitrust? Hardly! We should instead use more widely the method we apply to cartels: per se rules based on ordinary effects disdaining the search for rare counter-examples." ${ }^{\prime 1}$

The issue of legal uncertainty has attracted attention in recent years for another reason. Thus, legal experts have stressed that the increased tendency to use Effects-based procedures should have been associated with a reduction in the level (or even removal) of fines imposed, though the reverse has been the case. Thus Dethmers and Engelen (2011) note that "the European Commission recently imposed a record fine of 1.06 billion euro on Intel for having abused its dominant position by employing conditional rebates.... despite the adoption by the Commission of a more effects-based approach under art. 102 (TFEU) ${ }^{12}$ " The authors go on to argue that from a legal perspective the imposition of fines requires that "the Commission and courts must present evidence of intent or negligence in accordance with the principle of nulla poena sine lege certa ${ }^{13}$. In terms of policy it does not make sense to impose such high fines for anti-competitive behaviors, which are not per se illegal..."

In this paper we propose a formalisation to the concept of legal uncertainty which allows us to extend and generalise significantly our previous analysis Katsoulacos and

\footnotetext{
11 The issue has gained even more in importance recently as CAs worldwide have adopted significant reforms in decision and enforcement procedures, with an increasing use of Effects-Based rather than Per Se procedures. Examples include the adoption of a Rule-of-Reason standard for treating RPM in US, in the recent Leegin case (2007) - see for a discussion, Katsoulacos and Ulph (2009) - and the reforms in the assessment of article 102 practices by EU and national authorities (see the Commission Guidance Paper, 2008). These have followed earlier reforms adopting Effects-Based assessment procedures in merger, vertical and certain horizontal agreement cases. See also Katsoulacos and Ulph (2011), Kokkoris and Lianos (2008), Will and Schmidtchen (2008).

${ }^{12}$ Very high fines were imposed also in Microsoft and other recent cases - see for a review p. 86 - 89 of Dethmers and Engelen (2011). As the authors also note "The courts do not appear to impose any constraint on the Commission's discretion" to impose very high fines - p. 91.

${ }^{13}$ This Latin phrase may be translated as "no penalty unless there is certainty under the Law".

${ }^{14}$ Ibid. p. 98.
} 
Ulph $(\mathrm{K} \& \mathrm{U}, 2009)^{15}$, in which we undertook an welfare comparison of Per Se and Effects-Based legal standards, assuming, for the latter case, a specific information structure that we now call Partial Legal Uncertainty. In addition, in K\&U (2009) we assumed fixed penalties. Here we allow for different information structures under EffectsBased procedures - namely what we will call No Legal Uncertainty and Complete Legal Uncertainty - and also we allow the competition authority to adjust penalties depending on both the legal standard that is employed and the information structure that prevails. ${ }^{16}$ The model is set out in Section 2. In Section 3 we discuss its relation to the existing literature. In Section 4 we establish the welfare levels under the different information structures and in Section 5 we establish and discuss our main results. In summary, these are as follows:

1. Generally, when firms know their type ${ }^{17}$ (whether their actions are harmful or benign) but are uncertain about the CA's potential assessment of these actions (so there is Partial Legal Uncertainty), welfare may be higher than when firms face no legal uncertainty (Proposition 1), this being certainly the case with optimal endogenously set penalties (Proposition 2). This result echoes a similar finding obtained in a completely different context and different assumptions in the earlier Law and Economics literature by Kaplow and Shavell (1992).

2. Turning to a comparison of Effects-Based to Per Se legal standards, Effects-Based welfare dominates Per Se when in the former there is No Legal Uncertainty and may dominate Per Se when in the former there is Partial Legal Uncertainty (Proposition 1). This last result is the result of $K \& U$ (2009) and $K \& U$ (2014) with exogenously set penalties. The intuition is that under Partial Legal Uncertainty there is a differential deterrence effect - the fraction of harmful actions deterred is greater than that of benign actions - and the conclusion will hold when this effect is strong enough. Further, under an Effects-Based legal

\footnotetext{
${ }^{15}$ See also Kwak (2010) that deals with related issues to those discussed here, concerning judicial errors and the choice of the liability standard.

${ }^{16}$ As in K\&U (2009), we ignore the potential cost advantage of decision-making under Per Se as compared to Effects-Based rules as an additional factor favouring Per Se. This is readily incorporated and we have no new insights to offer on this issue. See Christiansen, A. and W. Kerber. (2008).

${ }^{17}$ Or, state of the world (below we refer to this as the "environment").
} 
standard, No Legal Uncertainty and Partial Legal Uncertainty welfare dominate Complete Legal Uncertainty (Proposition 1).

3. With optimally set endogenous penalties, there is an unambiguous welfare ranking of legal standards and information structures. For a given Effects-Based procedure, welfare is higher when there is Partial Legal Uncertainty than it is with No Legal Uncertainty that is in turn higher than when there is Complete Legal Uncertainty ${ }^{18}$. Further the latter welfare dominates Per Se (Propositions 2a and $2 b)$.

4. Administrative effectiveness improves welfare under Complete Legal Uncertainty but not so under Partial Legal Uncertainty with optimally set penalties (Propositions 2c and 2d).

5. Under an Effects-Based procedure the penalty chosen by the CA when there is Partial Legal Uncertainty will be higher than when there is No Legal Uncertainty and also higher than under the corresponding Per Se standard (Propositions 3a and $3 \mathrm{~d})$. The intuition is that legal uncertainty reduces the anticipated likelihood that an action will be disallowed and, to compensate for this and establish the desired deterrence level, the CA has to increase the level of penalties.

6. When there is Complete Legal Uncertainty there are circumstances where the Competition Authority will want to have no deterrence and so set a zero penalty, while in others it will want to have deterrence in which case, for the reasons given above, it will set a higher penalty than under Partial Legal Uncertainty (Propositions $3 b$ and $3 c)^{19}$. Thus we find limited support for the legal principle of nulla poena sine lega certa.

\section{Basic Set Up - Modelling Legal Uncertainty}

\subsection{Actions and Timing of Game}

\footnotetext{
${ }^{18}$ As explained below, Complete Legal Uncertainty is the situation where both of the potential dimensions of uncertainty are present: firms do not know the true type of their actions and are also uncertain about how an error-prone authority will assess these actions were they to be detected and investigated.

19 These results on optimal penalties are entirely consistent with the Beckerian tradition (Becker, 1968) as we discuss in Section 5.
} 
There is a population of firms of size 1 that could take a particular type of action which is potentially prohibited under Competition Law. Nature initially decides the fraction of this type of action $\gamma, 0<\gamma<1$ that comes from a Harmful $(\mathrm{H})$ state of the world or environment. Actions from the $\mathrm{H}$ state of the world, that are not stopped by a $\mathrm{CA}$, generate a social harm that is measured by the negative of the change in consumers' surplus, and denoted by $h_{H}>0{ }^{20}$. The remaining fraction of this type of action comes from a Benign (B) environment ${ }^{21}$, generating harm that we denote by $h_{B}<0$. Let $\bar{h}=\gamma h_{H}+(1-\gamma) h_{B}$ be the average harm for this type of action. A type of action is said to be Presumptively Legal (resp. Illegal) if $\bar{h}<0 \quad($ resp. $\bar{h}>0)$. We assume that $\gamma$ is common knowledge.

In the absence of any intervention by a CA, taking an action will confer a private benefit $b>0$ for the firm ${ }^{22}$. The distribution of $b$ is independent of the environment from which the firm comes ${ }^{23}$. We suppose that the private benefit has a positive continuous probability density $f(b)>0$ on $[0, \infty)$ with cumulative distribution function given by $F(b), \quad 0<F(b)<1 ; \quad F^{\prime}(b)=f(b)>0$.

Given the fraction (or ex ante probability) of $\mathrm{H}$ and $\mathrm{B}$ environments, firms decide whether or not to undertake an action taking into account information about its true nature ( $\mathrm{H}$ or $\mathrm{B})$ as well as the presence of a $\mathrm{CA}$ and the latter's enforcement and decision procedures. Finally, the $\mathrm{CA}$ if it detects an action, it investigates it and penalizes the firm taking the action if it considers it to be unlawful.

\subsection{Competition Authority Enforcement and Decision Procedures}

The CA detects and initiates enforcement procedures against a fraction $\pi, 0<\pi \leq 1$ of the actions taken. These enforcement procedures include verifying that a

\footnotetext{
${ }^{20}$ This is the substantive standard used by most Competition Authorities - see Motta (2004) or O'Donohue \& Padilla (2007) - and employed in our previous paper - K\&U (2009). It is the standard advocated by Salop (2010). It differs from a total welfare standard that would include the private benefit to the firm taking the action - advocated by Carlton (2007). The implications of using a total welfare standard are examined in K\&U (2015).

${ }^{21}$ Subsequently we will use the term "environment" to refer to the "states of the world" H or B.

${ }^{22}$ Which we take to be the present value of the expected change in profits from the action over its 'natural' lifetime.

${ }^{23}$ The "symmetry" assumption - see K\&U (2009), which also discusses implications of its relaxation.
} 
potentially anti-competitive action has been taken by the firm and, in the case of an Effects-Based decision rule, carrying out an investigation into its potential harm. We refer to $\pi$ as the coverage rate. In addition we assume that it takes time for the Authority to complete these enforcement procedures and reach a decision. We capture this through the fraction $\delta, 0 \leq \delta \leq 1^{24}$ of the private benefit and social harm that accrue if the Authority decides to disallow the action. We refer to this as the delay. We combine coverage rate and delay into a measure of the administrative effectiveness of the CA given by the parameter $\alpha=\pi(1-\delta), \quad 0 \leq \alpha \leq 1$.

We assume that the decision rule used by the authority is to set liability standard ${ }^{25}$ $\underline{h}$ and then disapprove the action taken by firm $k$ iff

$$
h_{k}^{e}>\underline{h}
$$

where $h_{k}^{e}$ denotes signal received by the CA on the environment of firm $k$ or the authority's estimate of the harm caused by firm $k$. While in principle the liability standard may be positive negative or zero and while below we could permit the possibility that firms do not know the liability standard, since we are going to allow the possibility that one of the reasons why they may not know for sure what decision the authority will make in their case is that they don't know what estimate of harm the authority will make, and since the decision rule depends simply on the difference between the estimate of harm and the liability standard, it will simplify the analysis if we assume that firms know the liability standard, and, furthermore that this is normalised so that $\underline{h}=0$.

Given this we assume that the CA can use one of two decision procedures.

Per Se Here the CA allows all actions of a given type if that type is Presumptively Legal and disallows all actions if the type is Presumptively Illegal. Consequently, for any given type of action, only one type of decision error is made by the CA: Type I (False Convictions) if the type of action is Presumptively Illegal and Type II (False Acquittals) if it is Presumptively Legal.

\footnotetext{
${ }^{24}$ For simplicity we assume in this paper that the delay is the same whatever legal standard is used.

${ }^{25}$ That is, the threshold level of harm caused by an action such that if the authority perceives the harm caused by a firm's action to be above this threshold it will disallow and penalise the action, while if the perceived level of harm is below this threshold then the authority will allow the firm's action.
} 
Effects-Based Under this procedure the CA undertakes an investigation of each action that comes before it, as a result of which it gets an estimate or a signal of the likely harm caused by the action. This signal, which is only imperfectly correlated with the true harm, will be either: "Positive Harm" indicating that on the basis of the evidence obtained the CA thinks the action is likely to reduce welfare; or "Negative Harm", indicating that the action is likely to increase welfare. The CA's decision rule is to disallow an action if it gets a Positive Harm signal and allow it if it gets a Negative Harm signal.

The quality of the CA's estimate of harm is embodied in the parameters $p_{B}, \quad 0<p_{B}<1$ - the probability that a Benign action generates a Negative Harm signal and $p_{H}, \quad 0<p_{H}<1$ - the probability that a Harmful action generates a Positive Harm signal. We assume that the CA's estimates have some discriminatory power so that $p_{B}+p_{H}>1$, so firms from the Harmful environment are more likely to generate a Positive Harm signal than are firms from the Benign environment, and vice versa ${ }^{26}$.

We are interested in the question of whether legal uncertainty would ever be a reason for preferring a Per Se procedure to an Effects-Based one in situations where there was a prima facie reason to prefer to use Effects-Based, and we take that prima facie reason to be that the Effects-Based procedure has lower decision error costs ${ }^{27}$ than Per $S e$. In Katsoulacos \& Ulph (2009) we establish the condition for this to be true, which we assume to hold here. Specifically, we make:

ASSUMPTION 1 An Effects-Based Procedure Has Lower Decision-Error Costs

If the action is Presumptively Legal - so $\bar{h}=\gamma h_{H}+(1-\gamma) h_{B}<0$ - then:

$$
\frac{p_{H}}{1-p_{B}}>\frac{(1-\gamma)\left(-h_{B}\right)}{\gamma h_{H}}>1
$$

(ii) If the action is Presumptively Illegal - so $\bar{h}=\gamma h_{H}+(1-\gamma) h_{B}>0$ - then:

\footnotetext{
${ }^{26}$ Note that, as in K\&U (2009) it is not necessary for the analysis that follows to use a more restrictive assumption such as that $p_{j}>(1 / 2), j=H, B$

${ }^{27}$ In Katsoulacos \& Ulph (2009) we say that in this case the Effects-Based procedure can effectively discriminate.
} 


$$
\frac{p_{B}}{1-p_{H}}>\frac{\gamma h_{H}}{(1-\gamma)\left(-h_{B}\right)}>1
$$

Assumption 1(i) guarantees that the average welfare of the actions that are disallowed will be negative, while 1(ii) guarantees that the average welfare of actions that are allowed is positive. It is straightforward to show that if an action is Presumptively Legal then (1) implies (2), while if it is Presumptively Illegal then (2) implies (1). So from now on we assume that both (1) and (2) hold ${ }^{28}$.

Fines

In general fines can take the form of a fixed penalty plus a component that is proportional to the private benefit, $\delta b$, that is obtained by the firm ${ }^{29}$ taking also account of the duration, $\delta$, over which this benefit accrues owing to the delay in reaching a decision and stopping the action. The fixed component reflects the desire to link the penalty to the social harm that an anti-competitive action causes, while the proportional component reflects the desire to create deterrence by eliminating the private benefit of firms by acting anti-competitively. Formally our assumption is that if a firm with private benefit $b>0$ has its action disallowed after a delay, $\delta$, it has to pay a penalty $\psi+\varphi \delta b, \quad \psi \geq 0, \varphi \geq 0$.

\subsection{Formalisation of Legal Uncertainty}

We assume that firms know whether the CA is using a Per Se or an Effects-Based procedure, and that, if it is Per Se, whether it is Per Se Legal or Per Se Illegal. When an Effects-Based procedure is used we make the assumption:

ASSUMPTION 2 All firms know the parameters $p_{B}, p_{H}$. Further, we assume that firms know the liability standard, $\underline{h}=0$

Here we propose an approach to the formalisation of legal uncertainty, which can be termed the information structure approach ${ }^{30}$. By information structure_we mean what

\footnotetext{
${ }^{28}$ In expressions (1) and (2) the LHS captures the quality of the CA's assessment while the RHS captures the "strength of the presumption of legality (resp. illegality)". See for details Katsoulacos \& Ulph (2009).

${ }^{29}$ There is an extensive literature on fines and law enforcement - see in particular the survey of Polinsky and Shavell (2000). For treatments that address fines under antitrust law see Buccirossi and Spangolo (2006), Wils (2006) and K\&U (2013).

${ }^{30}$ This, of course, relies on the main ideas introduced in the different strands of the existing literature, concerning the nature and sources of this phenomenon, to which we return below.
} 
agents know about the factors that influence the outcome of the CA's decision-making process. It is very important to distinguish what agents know about this process from the errors made in reaching decisions. What agents know, influences their perceived probability of being disallowed and it is on the basis of this perceived probability that we distinguish different information structures.

To clarify the difference between this approach and one that associates legal uncertainty with decision errors we start by noting that decision errors made by the authority are neither necessary nor sufficient for the existence of legal uncertainty. Thus:

(i) It is not true that if there are no errors there will be no legal uncertainty. This would only be true if also agents knew their type, that is, if they know the true value of the harm that their action causes to others.

(ii) It is also not true that when there are errors there will be legal uncertainty. After all, as noted, it is common to consider as an advantage of Per Se legal rules, that they do not involve legal uncertainty but of course Per Se legal rules can involve a substantial amount of decision errors.

Now, given our basic set-up and assumptions, firms' perceived probability of having their actions disallowed would be influenced by:

(i) Whether or not they know the true state $\mathrm{H}$ or $\mathrm{B}$, or their true type - the true value of harm on others that their action generates.

(ii) Whether or not they know the estimate of the harm of their action that the authority will make ( $h^{e}$, which depends on their understanding of exactly how the authority reaches its estimates of harm).

Accordingly there are 4 logically possible information structures that can arise.

(I) Firms know both whether their action is genuinely harmful or benign and also know whether, if investigated, it will be deemed to be harmful or benign.

(II) Firms know whether their action is genuinely harmful or benign but do not know whether, if investigated, it will be deemed to be harmful or benign.

(III) Firms do not know whether their action is genuinely harmful or benign but do know whether, if investigated, it will be deemed to be harmful or benign.

(IV) Firms neither know whether their action is genuinely harmful or benign nor know whether, if investigated, it will be deemed to be harmful or benign 
However, if firms know for sure whether or not their action will be deemed to be harmful or benign (cases (I) and (III)) it is not going to matter for either behaviour or welfare whether or not they know if their action is genuinely harmful. Consequently there are just three relevant information structures to consider:

\section{NLU) No Legal Uncertainty}

Here firms know for sure whether, if investigated, their action will be deemed to be harmful or benign (they know the CA's estimate ${ }^{31}, h^{e}$ ) but may or may not know for sure whether their action is genuinely harmful or benign. This implies that a fraction $p_{H}$ of firms from the Harmful environment will know for sure that their action will be disallowed, while the remaining fraction know for sure that it will be allowed. Similarly a fraction $p_{B}$ of firms from the Benign environment will know for sure that their action will be allowed, while the remaining fraction know for sure that it will be disallowed ${ }^{32}$.

\section{PLU) Partial Legal Uncertainty}

Here firms know for sure whether their actions are truly harmful or truly benign, but do not know for sure whether, if investigated, their action will be deemed to be harmful or benign (they do not know the CA's estimate $h^{e}$ ). However, all firms understand what is the distribution of errors in the authority's estimates and this allows each firm to calculate the probability of being convicted if investigated given its type. Thus all firms from the Harmful environment know that there is a probability $p_{H}$ of having their action disallowed, while all firms from the Benign environment know that there is a probability $p_{B}$ of having their action allowed.

\section{CLU) Complete Legal Uncertainty}

Here firms neither know for sure whether, if investigated, their action will be deemed to be harmful or benign nor do they know for sure whether their action is genuinely harmful

\footnotetext{
31 This could arise if the CA set out the factors it would measure, the data it would use to measure these, and the calculations it would make, and if firms could costlessly access exactly the data the CA would use in its particular case and perform the calculations before it decided to take the action.

${ }^{32}$ In contrast to the case of Partial Legal Uncertainty (below), under NLU firms of different type may face the same probabilities of being allowed or disallowed (convicted). Though in certain contexts this will be an unrealistic situation nevertheless it serves to make the point that even though the CA is using an EffectsBased procedure there still could be no legal uncertainty and that variability of decision across otherwise identical firms does not necessarily imply that there is legal uncertainty.
} 
or benign. We assume that here all firms assess the probability of conviction as $\bar{p}=\gamma p_{H}+(1-\gamma) \cdot\left(1-p_{B}\right)$.

For simplicity, in what follows we make the following additional assumption, though almost all our results go through without $\mathrm{it}^{33}$.

ASSUMPTION 3 All firms face exactly the same type of legal uncertainty.

\subsection{Behaviour of Firms}

Clearly if a firm knows for sure that, if investigated, its action will be allowed by the CA, penalties are irrelevant, and it will take the action whatever the penalty.

Consider then a firm that anticipates some positive probability $\beta, 0<\beta \leq 1$ of having its action banned/disallowed by the CA should it ever be investigated. Since it anticipates a probability $\pi, \quad 0<\pi<1$ of being investigated, and a delay $\delta, \quad 0 \leq \delta \leq 1$ in having the decision to disallow taken, its expected net benefit from taking the action is

$$
b\{[1-\beta \pi(1-\delta)]-\beta \pi \varphi \delta\}-\beta \pi \psi,
$$

which we can write as

$$
\beta \pi\{b[\Phi(\beta)-\varphi]-\psi\}
$$

where

$$
\Phi(\beta)=\left(\frac{1}{\beta \pi}-1\right)+\delta>0^{34}
$$

. There are then two cases. If:

$$
\varphi \geq \Phi(\beta), \text { the firm cannot make a profit by taking the action, whatever the }
$$
value of $b$ and $\psi$;

\footnotetext{
${ }^{33}$ More precisely, if there were fixed but unknown fractions of firms facing different types of legal uncertainty, and if these were random subsets of the population of firms, then the welfare rankings of legal standards and of information structures that we derive in Section 4 will go through. The only result that would change would be that the CA would set just one level of penalty - that which applies when there is what we call Complete Legal Uncertainty.

${ }^{34}$ Since the parameters $\pi$ and $\delta$ are constant throughout the paper, we have suppressed the dependence of on them and focused solely on its dependence on the probability of being disallowed, which varies across legal standards and information structures.
} 
(ii) $\varphi<\Phi(\beta)$ then taking the action is profitable for all values of

$$
b>\frac{\psi}{\Phi(\beta)-\varphi} \geq 0
$$

So the interpretation of $\Phi(\beta)$ is that it is the critical value of the proportional component of the penalty above which all actions will be deterred, and below which some actions will be taken - potentially all if the penalty is purely proportional $(\psi=0)$. This critical value is higher:

- the lower is the probability of being investigated;

- the lower is the probability of having the action disallowed if investigated;

- the longer the delay in reaching a decision.

This generalises the analysis appearing in typical treatments in the literature on law enforcement $^{35}$, where the critical value depends typically on just the first of these factors - the probability of detection - since it is implicitly assumed that conviction rates are 1 and there are no delays in decision-making.

Notice also that the case where the action will certainly be allowed - $\beta=0-$ can be handled as a special case of the above analysis by defining $\Phi(0)=\infty$

Drawing this discussion together, we see that for a group of firms with an anticipated probability $\beta, \quad 0 \leq \beta \leq 1$ of having their action disallowed by the $\mathrm{CA}$, the fraction $(D)$ of firms deterred from taking the action under any given penalty regime $\varphi, \psi$ is:

$$
D(\beta, \varphi, \psi)= \begin{cases}F\left[\frac{\psi}{\Phi(\beta)-\varphi}\right] & \text { if } \varphi<\Phi(\beta) \\ 1 & \text { if } \varphi \geq \Phi(\beta)\end{cases}
$$

As we will see, it turns out that if the CA can choose the penalty, it will want to deter either all or none of the firms from such a group. It can deter all firms by setting $\varphi=\Phi(\beta)$ and $\psi=0$, whereas it can deter none by setting $\varphi<\Phi(\beta)$ and $\psi=0$. So, given our other assumptions, the CA can achieve its objectives by using penalties that are purely proportional to private benefit. In what follows we assume that, when the CA can

\footnotetext{
${ }^{35}$ See, for example, the review article by Polinsky and Shavell (2000) or Buccirossi and Spangolo (2006).
} 
choose its penalty, it will indeed always choose a purely proportional penalty ${ }^{36}$. The dependence of the critical value of the penalty on the probability of an action's being disallowed means that the penalty chosen will vary depending on both the legal standard in force and the information structure - the type of legal uncertainty.

\section{Relation to Existing Literature}

While one legal expert has noted that there is an "absence of rigorously defined yet practical measures of legal uncertainty" 37 , the concept, loosely defined as the lack of ability to predict the outcome of a legal dispute, has been subject to extensive discussion by economists and legal experts. Calfee and Craswell (1984) offer an excellent informal review of early contributions, and, in a follow-up article - Craswell and Calfee (1986) provide more formal analysis. They stress two potential sources of legal uncertainty.

The first is uncertainty regarding the liability standard. The second source of legal uncertainty, which has since received much more extensive attention in the literature $^{38}$, arises because authorities are unable to determine the actual harm caused by an action and so have to form some estimate of the harm, and an action is disallowed if the estimated value of harm is above the liability standard. Since these estimates contain errors this gives rise to possible Type I and Type II decision errors whereby actions that should be allowed are disallowed and actions that should be disallowed are allowed.

In their analyses, Craswell and Calfee $(1984,1986)$ examine welfare implications of the above considering more specifically how under-compliance and over-compliance are affected. ${ }^{39}$ Following Craswell and Calfee $(1984,1986)$, many papers in the Law and Economics literature have used models in which, as in our model above, agents that undertake privately beneficial but socially harmful actions can face uncertainty along two dimensions, specifically, either (a) because they do not know whether their actions are or

\footnotetext{
${ }^{36}$ The purely proportional assumption can also be justified by an appeal to a principle of proportionality the CA uses the smallest penalty necessary to achieve its deterrence objectives. For a recent discussion of these issues see K\&U (2013) and Huba H et.al (2013).

${ }^{37}$ Davis (2011), p. 1.

${ }^{38}$ For example, in the context of competition policy, Schinkel et.al. (2006), Kwak J (2010) and Lang M (2012), Also, in the context of the general Law and Economics literature, see references mentioned below. ${ }^{39}$ Other analyses discussing implications of decision / judicial errors include Kaplow (1994), Png (1986), Schinkel et.al. (2006) and Lang (2012), Schwartztein et.al (2012) and Immordino et.al. (2014).
} 
are not harmful or/and (b) because they do not know how their actions will be treated by a social authority, the decisions of which are subject to errors. If actions are detected and, following an investigation, are found harmful they are subject to sanctions, also as in our model. This literature includes the important papers by Kaplow (1990), Kaplow (1995) and Kaplow and Shavell (1992). Kaplow (1990) examines the issue of optimal sanctions on agents that may be uncertain about whether their actions are harmful and thus sanctionable, though they may become perfectly informed at a positive cost. Specifically, the paper addresses three questions: if sanctions can be differentiated, is their optimal level the same for informed and uninformed agents? If sanctions must be the same, is the value of the optimal sanction affected by the presence of uninformed agents? And, when is it efficient for a tribunal to undertake the cost required in order to apply differential sanctions? Kaplow (1995) uses a similar setting, but with actions differing in their level of harm and examines the issue of whether it is welfare improving for a tribunal to undertake the cost of differentiating between actions of different harm by using more complex legal rules and setting different sanctions depending on the harm. Kaplow and Shavell (1992) uses a model closer in spirit than all other models in the literature to our model in the sense that agents face uncertainty because they may not know their true type or because of errors made in determining true harm by the social authority. Agents can obtain legal advice in order to eliminate both of these sources of uncertainty and the analysis examines whether the demand for such advice is socially appropriate. The analysis, although dealing with an issue (the demand for legal advice) completely different from the issues we are concerned with here and although, in most important respects, it utilises very different assumptions to those we utilise (see immediately below where we also interpret Kaplow and Shavell (1992) in terms of our framework), it leads to a result that seems to be an early precedent to one of the results also established below, namely that legal uncertainty may be welfare improving - Kaplow and Shavell (1992), Proposition $3^{40}$.

\footnotetext{
${ }^{40}$ Hylton (1990), extending Ordover (1978), could also be considered an early predecessor.
} 
There are very important differences between all the above papers and the present paper $^{41}$. So, in these papers the substantive standard used by the social authority for assessing whether an action is illegal is that of total welfare while we assume, as is much more natural in the context of competition law enforcement ${ }^{42}$, that the standard is that of consumer welfare. This is important given that the standard used influences in a critical way the deterrence objectives of the social authority and optimal penalties. Also, Kaplow (1990 and 1995) incorporate only one of the main dimensions of legal uncertainty - that related to agents not knowing their type. And, while Kaplow (1990) deals specifically with optimal sanctions, here we use a more general sanction structure that allows for both a penalty that is proportional to the private gain and a fixed part, to capture, respectively, both deterrence objectives and the objective to penalise the firm for the social harm its action causes, this structure also reflecting fining procedures in competition policy practice, while in Kaplow (1990) it is essentially assumed that there is a fixed penalty the optimal value of which is related to harm ${ }^{43}$. Furthermore, all three papers conflate the probability of being found illegal into a single number while it is important for our analysis to take explicitly into account that this probability is the product of two distinct probabilities, one of which is the probability of been detected to take a potentially harmful action and the other the probability that the authority, making decisions subject to errors, actually decides that the action is harmful. Finally, and very importantly, while in the context of the issues addressed by all the above papers it may be natural to assume, as the above papers do, that all potential actions undertaken by firms are non-benign ${ }^{44}$ (implicitly assuming a probability of allowing benign actions to occur equal to one and

\footnotetext{
${ }^{41}$ There are even greater differences also, apart from those mentioned below, to another even earlier strand in the Law and Economics literature that deals with important private litigation issues (not examined here) in situations where individuals do not know the extent to which other people are negligent though they know the average degree of negligence. Thus Ordover (1978) examines the implications of costly litigation for compliance in these contexts while Hylton (1990) extends the Ordover analysis by introducing judicial errors in assessing negligence, showing that these reduce the likelihood of not getting perfect compliance equilibria (and thus can increase, in this sense, welfare). As we have emphasized, the judicial errors, the implications of which are examined in Hylton, are not, as in most of the other Law and Economics literature mentioned in the text, the same as the legal uncertainty examined in this paper - and are neither necessary nor sufficient for the latter.

${ }^{42}$ It is standard practice for CAs to use a consumer surplus substantive standard - see Salop (2010), though among economists there are strong voices against too (e.g. Carlton, 2007).

${ }^{43}$ Note that interactions between the various differences in the assumptions mentioned here can also affect the results: e.g. it is easy to show that in Kaplow (1990), with a more general penalty structure the optimal structure depends on whether a total welfare or a consumer surplus substantive standard is assumed.

${ }^{44}$ That is, they generate positive or zero (but not negative) harm.
} 
thus neglecting Type I errors) $)^{45}$, this is certainly not the case for the sort of business practices dealt with by Competition Law, so in our framework we have to allow for actions that are either socially harmful or socially benign and to allow the authority's decision errors to extend to its assessment of the latter type of actions ${ }^{46}$.

In our proposed approach to the formalisation of legal uncertainty, based on the information structure of firms, legal uncertainty relates solely to what firms know about the decision that will be made should their action be investigated under a given decision procedure used by the CA. Since the decision rule is fixed, so too are the associated costs of the Type I and Type II errors to which it gives rise, and the different information structures matter solely because of the different deterrence effects that they generate due to the different perceived probabilities of conviction to which they give rise. A number of additional remarks are likely to be useful.

If there is No Legal Uncertainty, amongst firms who will be convicted, those whose actions are more harmful perceive no greater probability of conviction than those whose actions are less harmful. Similarly amongst firms whose actions will not be convicted. So, in that sense, there is no differential deterrence effect. While there is some statistical sense in which there is a differential deterrence effect at work - on average actions which are more harmful will be more likely to be deterred than actions that are less harmful, this does not happen at the level of individual firms.

With Partial Legal Uncertainty, on the other hand, there is a strong differential deterrence effect since all firms whose actions are more harmful will face a higher probability of conviction than those whose actions are less harmful. Finally, under Complete Legal Uncertainty there is absolutely no differential deterrence effect since all firms perceive exactly the same probability of conviction. As we show these generate important welfare consequences.

\footnotetext{
${ }^{45}$ An alternative way to put this is to say that Kaplow (1990) just deals with actions that in the terminology below, are presumptively illegal while we also have to consider presumptively legal actions. This also has serious implications for the results we get on optimal penalties under the different information structures.

${ }^{46}$ An additional difference between the above papers and the present one is that we examine the important phenomenon of desistance, i.e. how delays in the authority's procedures affects the outcomes. Agents' anti-competitive actions will normally take some time before they create benefits and social harm and so the size of these accruing will depend critically on delays in the authority's procedures, which therefore will affect the value of optimal sanctions (see also, K\&U, 2013).
} 
Interpreting Kaplow and Shavell (1992)

As mentioned above, in Kaplow and Shavell's (1992) set-up agents also either do not know whether their action is harmful or are uncertain about the authority's errorprone decisions were their action to be investigated. Using their terminology, agents can be "uninformed" because of either of these types of uncertainty. They can eliminate the uncertainty and become "informed" by getting "legal advice" at a cost. The paper examines whether the demand for legal advice is optimal. In terms of the framework used here, we can say that in Section 2 of their paper, agents' information structure is one of Complete Legal Uncertainty ${ }^{47}$ and by getting legal advice they move to No Legal Uncertainty. In their Section 3, agents' information structure is one of Partial Legal Uncertainty and by getting legal advice they move to No Legal Uncertainty. Proposition 3 (in their Section 3) essentially establishes that getting legal advice and moving from Partial to No Legal Uncertainty is not socially optimal - removing uncertainty reduces welfare. As we noted above, this result is established on the basis of a completely different set of assumptions to those utilised in this $\operatorname{paper}^{48}$. Further, here we are also primarily concerned, unlike Kaplow and Shavell (1992), with a comparison between different enforcement procedures ${ }^{49}$. With respect to this, note that while, as in Section 2 of Kaplow and Shavell (1992) we find that moving from Complete to No Legal Uncertainty reduces welfare, we also show the important result that moving from an Effects-Based procedure with Complete Legal Uncertainty to a Per Se procedure can also reduce welfare.

\section{Outcomes Under Different Enforcement Procedures and Different Information Structures}

In this section we set out the levels of welfare under different enforcement procedures and, in the case of an Effects-Based procedure, under different information

\footnotetext{
${ }^{47}$ In this section, agents can be uninformed about whether their action is harmful and if they become informed they learn the true harm that is what the authority will determine if it undertakes an investigation.

${ }^{48}$ The different issues examined in the two papers - demand for legal advice in Kaplow and Shavell (1992) vs. competition law enforcement here -can be considered responsible for the differences in assumptions.

${ }^{49}$ And not just with a comparison across information structures. While comparing different enforcement procedures was the subject also of $K \& U$ (2009), as noticed above, in that paper the analysis was restricted to one information structure and only exogenous penalties.
} 
structures. We do this for both the case where penalties are exogenous and the case where the CA chooses the optimal level of penalty.

\subsection{Effects-Based Procedure}

In this sub-section we assume that the CA uses an Effects-Based procedure, and that this has lower decision error costs than under the appropriate $\mathrm{Per} S \mathrm{Se}$ procedure, so both (1) and (2) hold. We consider in turn different information structures.

\subsubsection{No Legal Uncertainty}

Here a fraction $p_{B}\left(\right.$ resp. $\left.1-p_{H}\right)$ of firms from the Benign (resp. Harmful) environment know for sure that their action will be allowed and so will take it irrespective of the penalty. The remaining firms from each environment know for sure that, if investigated, their action will be disallowed, albeit after a delay. Since private benefit is uncorrelated with harm, then, for any given penalty, the same fraction

$$
D^{E B 0}= \begin{cases}F\left[\frac{\psi}{\Phi(1)-\varphi}\right] & \text { if } \varphi<\Phi(1) \\ 1 & \text { if } \varphi \geq \Phi(1)\end{cases}
$$

of these firms will be deterred from taking the action. Of those that take the action, harm will arise to the extent that only a fraction will be investigated, and, for those that are investigated, there will be a delay in reaching the decision to stop the action. So the harm generated will depend on the administrative effectiveness, $\alpha$. Consequently welfare under a given penalty is:

$$
\begin{aligned}
& W^{E B 0}(\alpha)=\left\{(1-\gamma)\left(-h_{B}\right) p_{B}-\gamma h_{H}\left(1-p_{H}\right)\right\}- \\
& \left(1-D^{E B 0}\right)(1-\alpha)\left\{\gamma h_{H} p_{H}-(1-\gamma)\left(-h_{B}\right)\left(1-p_{B}\right)\right\}
\end{aligned}
$$

The first term captures the welfare arising from those who know for sure that their action will be allowed, while the second is the expected welfare arising from those who know for sure that their action will be disallowed. Since the CA's rule is assumed to be able to effectively discriminate, actions that are allowed will on average be beneficial while those that are disallowed will on average be harmful. Hence, from (1) and (2), both the expressions in curly brackets are positive. This has two implications. 
The first is that welfare is a strictly increasing function of administrative effectiveness, $\alpha$.

The second is that if the CA could choose the penalty, it would like to deter all those firms who know for sure their action will be disallowed from taking it, so it would set a penalty

$$
\hat{\varphi}^{E B 0}=\Phi(1)=\left(\frac{1}{\pi}-1\right)+\delta, \quad \hat{\psi}^{E B 0}=0,
$$

giving rise to welfare:

$$
\hat{W}^{E B 0}=(1-\gamma)\left(-h_{B}\right) p_{B}-\gamma h_{H}\left(1-p_{H}\right)>0 .
$$

\subsubsection{Partial Legal Uncertainty}

Here, while no firm knows for sure whether their action will be allowed or disallowed, firms know the liability standard and so know for sure whether their action is Harmful or Benign. Firms from the Harmful environment anticipate that, if investigated, there is a probability, $p_{H}$ of having their action disallowed, albeit after a delay, whereas firms from the Benign environment anticipate a lower probability $1-p_{B}<p_{H}$ of an unfavourable decision by the CA. The fraction of firms from the Harmful environment that are deterred from taking the action is,

$$
D_{H}^{E B P}=\left\{\begin{array}{ll}
F\left[\frac{\psi}{\Phi\left(p_{H}\right)-\varphi}\right] & \text { if } \varphi<\Phi\left(p_{H}\right) \\
1 & \text { if } \varphi \geq \Phi\left(p_{H}\right)
\end{array},\right.
$$

while the fraction from the Benign environment that are deterred is

$$
D_{B}^{E B P}=\left\{\begin{array}{ll}
F\left[\frac{\psi}{\Phi\left(1-p_{B}\right)-\varphi}\right] & \text { if } \varphi<\Phi\left(1-p_{B}\right) \\
1 & \text { if } \varphi \geq \Phi\left(1-p_{B}\right)
\end{array} .\right.
$$

Note that since $1-p_{B}<p_{H}<1$, then $\Phi\left(1-p_{B}\right)>\Phi\left(p_{H}\right)>\Phi(1)$. Consequently if the penalty is so severe that all firms from even the Benign environment are deterred i.e. $\varphi \geq \Phi\left(1-p_{B}\right)$ - then we will have $D_{B}^{E B P}=D_{H}^{E B P}=D^{E B 0}=1$. However if $\varphi<\Phi\left(1-p_{B}\right)$ it will be the case that $D_{B}^{E B P}<D_{H}^{E B P} \leq D^{E B 0} \leq 1$. 
Whatever the penalty regime, welfare in this case is given by:

$$
W^{E B P}(\alpha)=(1-\gamma)\left(1-D_{B}^{E B P}\right)\left(-h_{B}\right)\left[1-\alpha\left(1-p_{B}\right)\right]-\gamma\left(1-D_{H}^{E B P}\right) h_{H}\left[1-\alpha p_{H}\right] .
$$

The first term gives the welfare arising from those firms from the Benign environment who take the action, taking account of the fact that a fraction $\alpha\left(1-p_{B}\right)$ of this will not materialise since some firms will be investigated and have their action disallowed, albeit after a delay. The second term is the analogous expression for firms from the Harmful environment.

If the CA can choose the penalty, it will want to ensure that NONE of the firms from the Benign environment are deterred, whereas ALL those from the harmful environment are deterred, and it can achieve this by setting a purely proportional penalty

$$
\hat{\varphi}^{E B P}=\Phi\left(p_{H}\right)=\left(\frac{1}{\pi p_{H}}-1\right)+\delta, \quad \hat{\psi}^{E B P}=0,
$$

giving rise to welfare:

$$
\hat{W}^{E B P}(\alpha)=(1-\gamma)\left(-h_{B}\right)\left[1-\alpha\left(1-p_{B}\right)\right]>0 .
$$

Notice that this level of welfare is a strictly decreasing function of the administrative effectiveness $(\alpha)$ of the CA, since, because it is only firms from the Benign environment that are not deterred, welfare is higher the fewer of these are investigated and the longer it takes to curtail their action in the event that it is both investigated and disallowed.

\subsubsection{Complete Legal Uncertainty}

Once again, no firm knows for sure whether their action will be allowed or disallowed, so there is legal uncertainty. But, in this case, firms do not even know their type, so all firms anticipate the same probability $\bar{p}=\gamma p_{H}+(1-\gamma)\left(1-p_{B}\right)<p_{H}$ of having their action disallowed if investigated. Accordingly the same fraction of firms

$$
D^{E B C}= \begin{cases}F\left[\frac{\psi}{\Phi(\bar{p})-\varphi}\right] & \text { if } \varphi<\Phi(\bar{p}) \\ 1 & \text { if } \varphi \geq \Phi(\bar{p})\end{cases}
$$


from each environment will be deterred from taking the action. If $\left.<\gamma_{\bar{p}}\right)$ so the penalty is sufficiently low that some firms do indeed take the action, then we will have $D_{B}^{E B P}<D^{E B C}<D_{H}^{E B P} \leq 1$.

For any given penalty regime welfare is

$$
W^{E B C}=\left(1-D^{E B C}\right) \bar{W}^{E B C}(\alpha)
$$

where

$$
\begin{gathered}
\bar{W}^{E B C}(\alpha)=(1-\gamma)\left(-h_{B}\right)\left[1-\alpha\left(1-p_{B}\right)\right]-\gamma h_{H}\left[1-\alpha p_{H}\right] \\
=-\bar{h}+\alpha\left[\gamma h_{H} p_{H}-(1-\gamma)\left(-h_{B}\right)\left(1-p_{B}\right)\right]
\end{gathered}
$$

is the average welfare generated by those firms which take the action when there is Complete Legal Uncertainty. Given our assumption that the CA's Effects-Based rule can Effectively Discriminate we see from (1) and (13) that the average welfare generated by those firms that take the action is a strictly increasing function of the administrative effectiveness of the $\mathrm{CA}, \alpha$, with

$$
\bar{W}^{E B C}(0)=-\bar{h} ; \quad \bar{W}^{E B C}(1)=(1-\gamma)\left(-h_{B}\right) p_{B}-\gamma h_{H}\left(1-p_{H}\right)>0
$$

where the sign of $\bar{W}^{E B C}$ (1) follows from (2) and hence our assumption that the EffectsBased rule can Effectively Discriminate.

In considering the implications for the penalty that would be chosen by the CA, and the associated level of welfare, two cases arise:

Case 1. Positive Average Welfare $\left(\bar{W}^{E B C}(\alpha)>0\right)$

From (14) and (13) it is easy to see that a sufficient condition for this case to arise is that the action is Presumptively Legal $(\bar{h}<0)$. In this case the CA will not want to deter any firm from taking the action, so the optimal penalty is:

$$
\hat{\varphi}_{+}^{E B C}=0, \quad \hat{\psi}_{+}^{E B C}=0
$$

and the associated level of welfare is:

$$
\hat{W}_{+}^{E B C}(\alpha)=\bar{W}^{E B C}(\alpha)>0 .
$$

Case 2. Negative Average Welfare, $\left(\bar{W}^{E B C}(\alpha)<0\right)$ 
Once again it is straightforward to see from (13) and (14) that a necessary condition for this to arise is that the action is Presumptively Illegal $(\bar{h}>0)$. In this case, the CA will want to deter all firms from taking the action in which case

$$
\stackrel{\triangle E B C}{\triangle}=(\bar{p})=\left(\begin{array}{cc}
\frac{1}{\bar{p}} & 1
\end{array}\right)+, \quad \wedge E B C=0
$$

and the associated level of welfare is:

$$
W^{E B C}=0 .
$$

Taking the two cases together we see that, when the CA can set the penalty, welfare under an Effects-Based legal standard when there is Complete Legal Uncertainty is

$$
W^{E B C}()=\operatorname{MAX}\left\{\bar{W}^{E B C}(), 0\right\} \text {. }
$$

\subsection{Per Se Procedure}

In this sub-section we assume that the CA uses a Per Se procedure whereby all actions will be either allowed by the CA if the action is Presumptively Legal or, if the action is Presumptively Illegal will certainly be disallowed (albeit with a delay) if the action is investigated by the CA. This is common knowledge so there is no legal uncertainty when such a legal standard is used. To understand the implications consider in turn two cases.

\subsubsection{Presumptively Legal Actions $(\bar{h}<0)$}

In this case all firms take the action whatever the penalty and the associated level of welfare is

$$
W^{P S L}=-\bar{h}>0 .
$$

Since penalties are irrelevant they can effectively be set to zero, so:

$$
\stackrel{\sim P S L}{ }=0, \quad{ }^{P S L}=0
$$

and, for completeness, welfare is:

$$
W^{P S L}=\bar{h}>0 \text {. }
$$




\subsubsection{Presumptively Illegal Actions $(\bar{h}>0)$}

In this case the same fraction of firms from both the Harmful and Benign environments will be deterred, namely

$$
D^{P S I}= \begin{cases}F\left[\frac{\psi}{\Phi(1)-\varphi}\right] & \text { if } \varphi<\Phi(1)=D^{E B 0}, \\ 1 & \text { if } \varphi \geq \Phi(1)\end{cases}
$$

and, of those who are not deterred, a fraction, $\pi$, will be investigated and have their actions disallowed after a delay, so welfare for any given penalty is:

$$
W^{P S I}(\alpha)=-\left(1-D^{P S I}\right)(1-\alpha) \bar{h} \leq 0 .
$$

This is a strictly increasing function of administrative effectiveness, $\alpha$, since, if actions

are on average harmful society is better off the higher the proportion investigated and the sooner they are stopped. If the CA can choose the penalty it will want to deter all actions and so will set a penalty

$$
\hat{\varphi}^{P S I}=\Phi(1)=\left(\frac{1}{\pi}-1\right)+\delta=\hat{\varphi}^{E B 0}, \quad \hat{\psi}^{P S I}=0,
$$

giving rise to welfare

$$
W^{P S I}=0 \text {. }
$$

So, in general, when the CA can choose the penalty, welfare under a Per Se procedure is

$$
W^{P S}=\operatorname{MAX}\{\bar{h}, 0\} .
$$

Remark 1 Inspection of the expressions for optimal penalties shows that:

(a) Optimal penalties will be zero in all cases other than with Effects-Based under Partial Legal Uncertainty when administrative effectiveness is perfect ( $\alpha=1$, i.e. $\pi$ $=1$ and $\delta=0)$.

(b) Optimal penalties will be positive even with perfect detection $(\pi=1)$ for as long as there are delays in decision making $(\delta>0)$. This will be true even under a Per Se Illegality rule (see expression (24)).

\section{Welfare Comparisons and Optimal Penalties: Main Results}


In this section we compare welfare under different procedures and information structures. We start, for later reference, with a result for the case where penalties are exogenously fixed.

Proposition 1 As established in K\&U (2014):

(i) If there is No Legal Uncertainty then an Effects-Based legal standard welfare dominates a Per Se legal standard.

(ii) Welfare can be higher under Partial Legal Uncertainty than under No Legal Uncertainty. If Partial Legal Uncertainty welfare dominates No Legal Uncertainty then a fortiori it welfare dominates Per Se. Even if welfare is lower under Partial Legal Uncertainty than under No Legal Uncertainty it may still be higher than under $\mathrm{Per} \mathrm{Se}^{50}$.

(iii) Partial Legal Uncertainty and No Legal Uncertainty welfare dominates Complete Legal Uncertainty. However, although an information structure in which there is Complete Legal Uncertainty is the worst information structure for an Effects-Based legal standard, there are conditions under which it welfare dominates the outcome under a Per Se legal standard. This result is strengthened with endogenous penalties.

Next, we compare the levels of welfare if penalties are not fixed but can be chosen by the CA to achieve its objective given the legal standard and information structure. We also compare optimal penalties across both legal standards and information structures.

Before undertaking these comparisons we note that in a First-Best world with costless perfect information, the CA would be able to investigate all actions, accurately and distinguish Harmful and Benign actions; instantly disallow the former while allowing the latter. All Harmful actions would therefore be deterred and all Benign actions allowed generating a First-Best welfare level

$$
W^{F B}=(1-\gamma)\left(-h_{B}\right) .
$$

Turning to the second-best world comparisons we will, for the sake of efficiency in presenting the results, show that the worst information structure under effects-based is not worse than Per Se, thus establishing that effects-based is always better than Per Se.

\footnotetext{
${ }^{50}$ See $\mathrm{K} \& \mathrm{U}$ (2009) for an extensive analysis and discussion of the conditions under which an Effects-Based legal standard with Partial Legal Uncertainty welfare dominates Per Se.
} 


\section{Welfare Comparisons}

The following inequalities follow immediately from (8), (11), (13), (19), (26) and (27):

$$
\begin{aligned}
& W^{F B}=(1-\gamma)\left(-h_{B}\right) \\
= & W^{E B P}(0) \\
\geq & W^{E B P}(\alpha)=(1-\gamma)\left(-h_{B}\right)\left[1-\alpha\left(1-p_{B}\right)\right] \\
& \quad=(1-\gamma)\left(-h_{B}\right) p_{B}+(1-\gamma)\left(-h_{B}\right)\left(1-p_{B}\right)(1-\alpha) \\
\geq & W^{E B P}(1)=(1-\gamma)\left(-h_{B}\right) p_{B} \\
> & W^{E B 0}=(1-\gamma)\left(-h_{B}\right) p_{B}-\gamma h_{H}\left(1-p_{H}\right) \\
= & W^{E B C}(1) \\
\geq & W^{E B C}(\alpha)=M A X\left\{-\bar{h}+\alpha\left[\gamma h_{H} p_{H}-(1-\gamma)\left(-h_{B}\right)\left(1-p_{B}\right)\right], 0\right\} \\
\geq & W^{E B C}(0)=\operatorname{MAX}\{-\bar{h}, 0\} \\
= & W^{P S}
\end{aligned}
$$

This establishes the following:

Proposition 2 When the CA can choose the appropriate penalty then there is a clear welfare ranking of information structures and legal standards. In particular:

(a) With an Effects-Based legal standard Partial Legal Uncertainty strictly dominates No Legal Uncertainty. Thus, with endogenous penalties, Proposition 1 is substantially strengthened. No Legal Uncertainty dominates Complete Legal Uncertainty - thus, the latter is the worst situation under Effects-Based.

(b) An Effects-Based legal standard with Complete Legal Uncertainty welfare dominates a Per Se legal standard. Given (a) this implies that Effects-Based is always better compared to Per Se.

(c) Under an Effects-Based legal standard with Partial Legal Uncertainty welfare is a strictly decreasing function of administrative effectiveness, $\alpha=\pi(1-\delta), \quad 0 \leq \alpha \leq 1$, with the First-Best level of welfare being attained when $\alpha=0^{51}$.

\footnotetext{
${ }^{51}$ See discussion in sub-section 4.1.2 above for the intuition of this result.
} 
(d) Under an Effects-Based legal standard with Complete Legal Uncertainty welfare is a strictly increasing function of administrative effectiveness, $\alpha$, achieving the same welfare as with No Legal Uncertainty when $\alpha=1$ and the same welfare as under Per Se when $\alpha=0$.

These results are also illustrated in Figures $1 \mathrm{a}$ and $1 \mathrm{~b}$ (see below).

\section{First Best Dominates Partial Legal Uncertainty}

When there is Partial Legal Uncertainty the CA can exploit the fact that firms know their type and the fact that, since its rule has discriminatory ability, fewer firms from the Benign environment will be disallowed than from the Harmful environment, to set a penalty that ensures no Harmful actions are taken while all Benign actions are taken, even though some of these may subsequently be investigated and stopped, albeit after a delay. The CA thus completely separates Benign from Harmful actions. If administrative effectiveness is zero all Benign actions are effectively allowed and the First-Best is attained. When administrative effectiveness is positive some Benign actions are ultimately stopped so welfare falls the greater is administrative effectiveness.

\section{Partial Legal Uncertainty Strictly Dominates No Legal Uncertainty}

There are two reasons why this result holds. First, with Partial Legal Uncertainty ALL Harmful actions are deterred, whereas, under No Legal Uncertainty, some firms from the Harmful environment will take the action knowing for sure that, given the CA's imperfect assessment, they will subsequently be allowed. Second, under No Legal Uncertainty, knowing for sure that they will subsequently be disallowed, a fraction of Benign actions will be deterred. This will be greater than or equal to the fraction of Benign actions that, though undeterred, will be stopped following an investigation under Partial Legal Uncertainty. ${ }^{52}$

No Legal Uncertainty Dominates Complete Legal Uncertainty.

\footnotetext{
${ }^{52}$ The fraction of Benign actions taken when there is No Legal Uncertainty will be the same as under Partial Legal Uncertainty only when there is complete administrative effectiveness.
} 
There are two cases to consider. The first is where, under Complete Legal Uncertainty, the average welfare were all firms to take the action is negative ${ }^{53}$ and consequently the CA would set a high penalty that deters ALL firms from taking the action, generating zero welfare. But then No Legal Uncertainty generates higher welfare since those firms that know for sure that their action will be allowed will take it and, on average, they generate positive welfare. The second case is where, under Complete Legal Uncertainty, the average welfare if all firms take the action is positive ${ }^{54}$, and consequently the CA will set a zero penalty and so deter no actions. But now welfare with Complete Legal Uncertainty is a strictly increasing function of administrative effectiveness since the only thing that reduces the harm created by firms taking the action are the decisions of the $\mathrm{CA}$, and, given it can effectively discriminate, the more actions it can get its decision-making ability to bite on and the faster it reaches its decision the higher is welfare. When there is complete administrative effectiveness and so all actions are investigated and decisions reached instantly, the remaining actions that are allowed will be exactly the same as those arising from those firms who know for sure their action will be allowed under No Legal Uncertainty.

\section{Effects-Based Standards with Complete Legal Uncertainty Dominate Per Se}

If the action is Presumptively Illegal then under Per Se the CA will set a penalty that will deter all actions. However this will happened under an Effects-Based standard with Complete Legal Uncertainty only if, in addition, administrative effectiveness is low. In this case both procedures produce zero welfare. However when the action is Presumptively Illegal but administrative effectiveness is sufficiently high, then, as we have seen, under an Effect-Based standard with Complete Legal Uncertainty the CA will want to set a zero penalty so no actions are deterred, but it then uses its ability to Effectively Discriminate to allow predominantly Benign actions so producing positive welfare. When the action is Presumptively Legal the CA will set zero penalties under both a Per Se legal standard and under an Effects-Based legal standard with Complete

\footnotetext{
${ }^{53}$ This arises only if the action is Presumptively Illegal and the degree of administrative effectiveness is low.

${ }^{54}$ This will arise either if the action is Presumptively Legal or if it is Presumptively Illegal but there is a sufficiently high degree of administrative effectiveness.
} 
Legal Uncertainty. But then in both cases all actions will be taken. However the power of the Effects-Based procedure to Effectively Discriminate will produce lower decisionerror costs and so higher welfare.

Remark 2 What this discussion brings out very clearly is that under an EffectsBased legal standard the CA can prevent actions either by deterrence - stopping them ever being taken - or desistance - investigating and stopping (possibly after a delay) those that have been taken - and that, through a careful choice of penalties, the balance between these two modes will shift in subtle ways depending on the informational structure and hence the extent of Legal Uncertainty faced by firms. Under a Per Se legal standard, if the action is Presumptively Illegal the CA makes it clear that any action that is taken will be stopped and combines this with a penalty that deters all actions. Whereas if the action is Presumptively Legal the CA neither deters nor desists any action. It is this much cruder nature of a Per Se standard that makes it unambiguously worse that an Effects-Based standard - whatever the degree of Legal Uncertainty.

\subsubsection{Comparison of Optimal Penalties}

From (7), (10), (15), (17), (21), and (24) we have the following inequalities:

$$
\begin{aligned}
0=\hat{\varphi}^{P S L}=\hat{\varphi}_{+}^{E B C}<\hat{\varphi}^{P S I} & =\hat{\varphi}^{E B 0}=\Phi(1) \\
<\hat{\varphi}^{E B P} & =\Phi\left(p_{H}\right) \\
<\hat{\varphi}_{-}^{E B C} & =\Phi(\bar{p})
\end{aligned}
$$

This establishes the following:

Proposition 3 Under an Effects-Based legal standard, the optimal penalty chosen by the CA will be ${ }^{55}$ :

(a) higher when there is Partial Legal Uncertainty than when there is No Legal Uncertainty

(b) higher still when there is Complete Legal Uncertainty and average welfare if all firms take the action is negative;

\footnotetext{
${ }^{55}$ Throughout this discussion we are assuming that there are no constraints to optimally set penalties e.g. constraints due to legal principles, such as that of "proportionality".
} 
(c) zero if there is Complete Legal Uncertainty and average welfare if all firms take the action is positive;

(d) higher under Effects-Based with Partial Legal Uncertainty than under Per Se for both presumptively legal and presumptively illegal actions;

(e) equal under Effects-Based with No Legal Uncertainty than under Per Se for presumptively illegal actions and higher under Effects-Based with No Legal Uncertainty than under Per Se for presumptively legal actions.

Thus in situations where there is legal uncertainty the appropriate penalty may be higher than when there is no legal uncertainty, though there is one class of cases where the appropriate penalty under Complete Legal Uncertainty is indeed zero. While this latter result is certainly consistent with the principle of nulla poena sine lega certa as advocated by Dethmers and Engelen (2011) and other legal scholars, there is no general support for this principle.

Remark 3 It is worth stressing that these results are entirely consistent with the Beckerian tradition on optimal penalties. As Becker (1968) had first noted the optimal penalty is higher when uncertainty is introduced in the form of imperfect detection. Here we show that if there is increased uncertainty in the form of imperfect understanding about how actions will be treated if investigated by a CA (the form of uncertainty that has preoccupied legal writings) this may raise optimal penalties - though this will not always be the case. As shown, this result holds also when there detection is perfect $(\pi=1)$.

\section{Concluding Remarks}

In this paper we have proposed a formalisation to the concept of "legal uncertainty" and have set this out in the context of competition policy, but the framework can apply more widely. Our approach identifies legal uncertainty purely with the information structure of what a firm knows about the process by which a CA would reach a decision should an action that the firm has taken be investigated by the authority. As such, legal uncertainty is distinct from the phenomenon of decision errors made by the authority, which are neither necessary nor sufficient for the existence of legal uncertainty. We distinguish three information structures with no legal uncertainty, partial legal uncertainty and complete legal uncertainty.. We compare these different information 
structures between themselves and with $\mathrm{Per}$ Se procedures and also compare penalties across different procedures and information structures.

Our analysis offers important grounds for scepticism about arguments coming mainly from legal experts, that Effects-Based procedures are less attractive than Per Se because of the Legal Uncertainty that they entail and that, if adopted, should involve much lower penalties according to the legal principle of nulla poena sine lege certa. Two important policy lessons emerge in particular from the analysis above.

First, enforcement procedures involving legal uncertainty may be welfare superior to those without any legal uncertainty because of their better deterrence effects. This is most likely when legal uncertainty arises because, although firms know their type, they cannot predict what the Competition Authority will decide in their case. Thus a decision by policy makers not to adopt Effects-Based procedures cannot be based solely or even mainly on arguments relating to the legal uncertainty of such procedures.

Second, the superiority of Effects-Based procedures is enhanced when Competition Authorities use penalties to achieve optimal deterrence effects. In that case it is never optimal to use Per Se. This is because under an Effects-Based legal standard the CA can prevent actions either by deterrence - stopping them ever being taken - or by desistance - investigating and stopping (possibly after a delay) those that have been taken. Under a Per Se legal standard, if the action is Presumptively Illegal the CA makes it clear that any action that is detected and investigated will be stopped and, to counter the risk of not being detected, combines this with a penalty that deters all actions. Whereas if the action is Presumptively Legal, the CA neither deters nor desists any action. It is this much cruder nature of $\mathrm{Per} S \mathrm{Se}$ procedures that makes them unambiguously worse that Effects-Based procedures whatever the type of Legal Uncertainty - a conclusion that runs directly counter to that proposed by many legal experts.

Finally, and more practically, our analysis shows that CAs may well be justified in raising their penalties after adopting Effects-Based procedures.

\section{References}

Becker G. S. (1968) “Crime and Punishment: An Economic Approach", Journal of Political Economy, 76. 
Buccirossi P and G Spagnolo (2006) "Optimal Fines in the Era of Whistleblowers", CEPR Discussion Paper 5465.

Christiansen, A. and W. Kerber (2006) "Competition Policy with Optimally Differentiated Rules Instead of "Per Se Rules Vs. Rule of Reason", Journal of Competition Law and Economics 2(2), 215-244.

Calfee J E and R Craswell (1984) "Effects of Uncertainty on Compliance with Legal Standards" Virginia Law Review, Vol.70 No. 5: 965 - 1003.

Carlton D. W. (2007), 'Does Antitrust Need to be Modernized?', Economic Analysis Group, Discussion Paper, EAG 07-3, January 2007.

Craswell, R and J E Calfee (1986), "Deterrence and Uncertain Legal Standards", Journal of Law, Economics \& Organisations, 2, pp 279-303.

D’Amato Anthony (1983) “Legal Uncertainty”, California Law Review 71, 1983.

Davis E. Kevin (2011) "The Concept of Legal Uncertainty," Canadian Law and Economics Association Annual Meeting, October 1, 2010; NYU Law and Economics Workshop, October 20, 2010; University of Chicago Law \& Economics Workshop, October 4, 2011.

Dethmers, F. and E. Engelen (2011) "Fines under article 102 of the Treaty on the Functioning of the EU" European Competition Law Review, Issue 2, pp. 86-98.

Easterbrook, F.H. (1992), 'Ignorance and Antitrust', in Jorde, TM, and Teece, DJ (eds), Antitrust, Innovation, and Competitiveness, Oxford University Press, pp 119-36.

European Commission (2008) “Guidance on the Commission's Enforcement Priorities in Applying Article 82 EC Treaty to Abusive Exclusionary Conduct by Dominant Undertakings".

Forrester Ian (2000) "The Modernisation of EC Antitrust Policy: Compatibility, Efficiency, Legal Security”, EUI, 2000 EU Competition Workshop.

Houba, H., Motchenkova, E. and Q. Wen (2013), "Legal Principles in Antitrust Enforcement", TI Discussion Paper 13-178/II, Amsterdam: Tinbergen Institute. http://papers.tinbergen.nl/13178.pdf

Hylton K.N (1990) "Costly Litigation and Legal Errors under Negligence", Journal of Law,Economics and Organisation, Vol. 6, No. 2. 
Immordino G. and M. Polo (2014) "Antitrust, Legal Standards and Investment", International Review of Law and Economics, 40: 36 - 50.

Kaplow, L. (1990) "Optimal Deterrence, Uninformed Individuals and Acquiring Information about Whether Acts are Subject to Sanctions", Journal of Law, Economics and Organisation, 6: 93 - 128.

Kaplow, L. (1994) "The Value of Accuracy in Adjudication: an Economic Analysis", Journal of Legal Studies, 15: 371 - 385.

Kaplow, L. (1995) “A Model of the Optimal Complexity of Legal Rules", Journal of Law, Economics and Organisation, 11 (1): 150 - 163.

Kaplow, L. and S Shavell (1995) "Private versus Socially Optimal Provision of Ex Ante Legal Advice", Journal of Law, Economics and Organisation, 8: 306 - 320.

Katsoulacos Y. and D. Ulph (2009) "Optimal Legal Standards for Competition Policy: A General Welfare-Based Analysis", Journal of Industrial Economics, Sept., Vol. LVII, No.3

Katsoulacos Y and D. Ulph (2011) "Optimal Enforcement Structures for Competition Policy: Implications of Judicial Reviews and of Internal Error Correction Mechanisms", European Competition Journal, March/April 2011.

Katsoulacos Yannis and David Ulph (2013). 'Antitrust Penalties and the Implications of Empirical Evidence on Cartel Overcharges', Economic Journal, Nov. 2013.

Katsoulacos Y and D. Ulph (2014) "Legal Uncertainty, Competition Law Enforcement Procedures and Optimal Penalties Taking into Account Administrative Effectiveness", Discussion Paper, available in Publications www.cresse.info, June 2014.

Katsoulacos Y and D. Ulph (2015) "Optimal Enforcement Procedures and Penalties under Legal Uncertainty and a Total Welfare Substantive Standard", Discussion Paper, available in Publications www.cresse.info.

Kokkoris I and I. Lianos (Eds) (2008), The Reform of EC Competition Law, Kluwer Publishers.

Kwak J. (2010) "Optimal Antitrust Enforcement: Judicial Standard, Judicial Error and Deterrence Affect", mimeo.

Lang, M. (2012), "Legal Uncertainty - an Effective Deterrent in Competition Law?" mimeo. 
Motta, M (2004), Competition Policy: Theory and Practice, Cambridge University Press.

O'Donohue, R and J. Padilla, (2007), The Law and Economics of Article 82E, Hart Publishing.

Ordover J. A (1978) "Costly Litigation in the Model of Single Activity Accidents", The Journal of Legal Studies, Vol. 7, No. 2.

Png I.P.L (1986) "Optimal Subsidies and Damages in the Presence of Judicial Error", International Review of Law and Economics, 6: 101 - 105.

Polinsky, M and S. Shavell (2000), "The Economic Theory of Public Enforcement of Law”, Journal of Economic Literature, pp 45-76.

Posner R (2010) "Economic Analysis of Law", $8^{\text {th }}$ Edition, Aspen Casebooks.

Salop, S (2010), "Question: What is the Real and Proper Antitrust Welfare Standard? Answer: The True Consumer Welfare Standard" Loyola Consumer Law Review, September.

Schinkel, M.P. and J. Tuinstra, (2006), "Imperfect competition law enforcement", International Journal of Industrial Organisation, 24, 1267-1297.

Schwartzstein J. and A. Shleifer (2012) "An Activity-Generating Theory of Regulation", Journal of Law and Economics, 56: 1 - 38.

Will, B.E. and D. Schmidtchen (2008), "Fightng Cartels: Some Economics of Council Regulation (EC) 1/2003", CSLE Discussion Paper, No. 2008-02.

Wils Wouter P. J. (2006), "Optimal Antitrust Fines: Theory and Practice", World Competition, Vol. 29, No. 2,

Vickers J. (2007), Economics and the Competition Rules, Speech delivered to the British Institute of International and Comparative Law. 
Figure 1a: Presumptively Legal

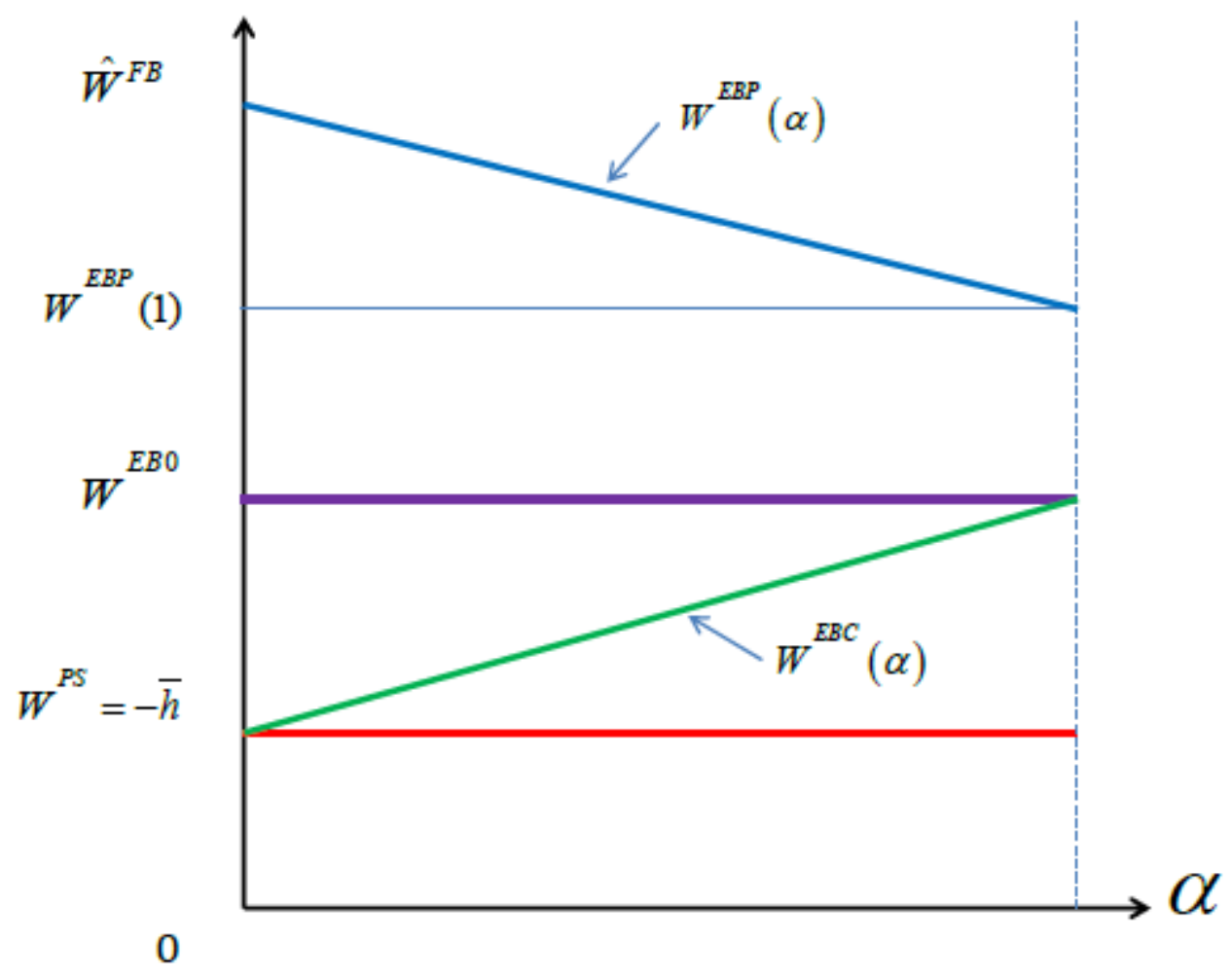


Figure 1b: Presumptively Illegal

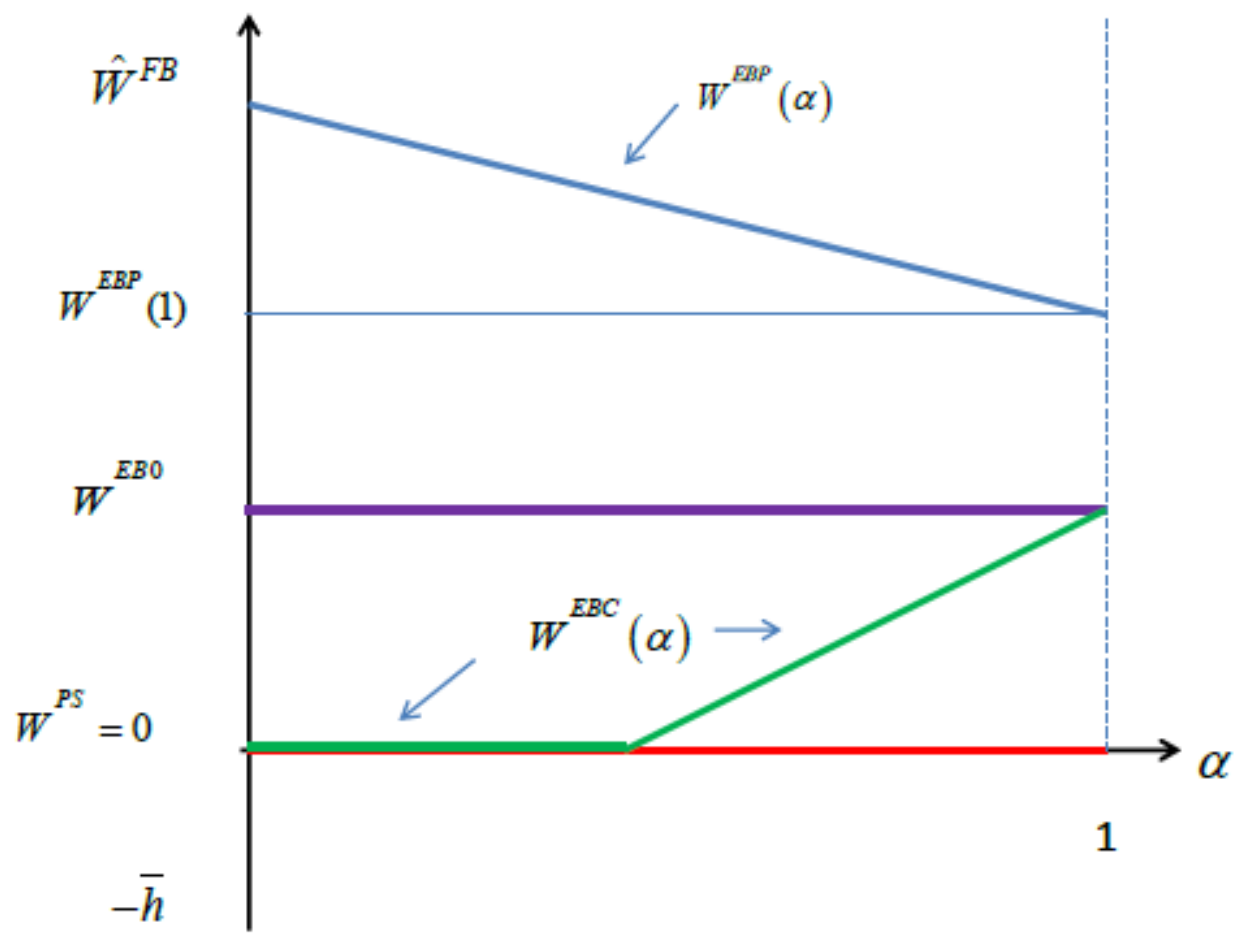

